\title{
A rat model of postthoracotomy pain: behavioural and spinal cord NK-1 receptor assessment
}

\author{
[Un modèle de douleur post-thoracotomie chez le rat : évaluation comportementale \\ et médullaire du récepteur NK-1]
}

Takeshi Nara MD, Shigeru Saito MD PhD, Hideaki Obata MD, Fumio Goto MD PhD

Purpose: To develop a new rat model of postthoracotomy pain for investigating its mechanisms and clarifying neurochemical changes.

Methods: Male Wistar rats were randomly assigned to three groups that underwent either fourth and fifth intercostal nerve ligation, cutting of the fourth and fifth ribs, or a sham operation in which only pleura was cut. For behavioural response assessment during the following month, pinch and touch were used as mechanical stimuli, and acetone was used as a cold thermal stimulus. In addition, ${ }^{125}$-substance $\mathrm{P}$ autoradiography was used to determine neurokinin (NK) receptor density in spinal cord laminae I and II at one to six weeks after surgery.

Results: In rats with nerve ligation, hypersensitivity to noxious and non-noxious stimuli continued throughout the month. The "mirror phenomenon" was observed. The lowest threshold was obtained in the dorsomedial portion of the T4 dermatome on the side of surgery. In rats with rib cutting, a lowered threshold to noxious and non-noxious stimuli was observed for two weeks. In rats with sham operations, hypersensitivity was seen only at postoperative day one. NK-I receptor density on the side of operation increased significantly in rats with nerve ligation from day seven to 28 . Receptor density was highest on day 14 (22.97 $\pm 1.04 \mathrm{fmol} \cdot \mathrm{mg}^{-1}$ tissue vs control, $16.22 \pm 0.43)$, representing a $50 \%$ receptor excess on the side of ligation compared to the contralateral side.

Conclusion: Intercostal nerve damage induces long-term postthoracotomy pain and an increase of spinal NK-I receptors in rats. This model may be useful for investigation of postthoracotomy pain.

Objectif : Élaborer un modèle de douleur post-thoracotomie chez le rat afin d'en explorer les mécanismes et d'en préciser les changements neurochimiques.

Méthode : Des rats mâles Wistar ont été répartis au hasard en trois groupes et on subi une ligature des quatrième et cinquième nerfs intercostaux, ou la section des quatrième et cinquième côtes ou une opération fictive comportant une incision de la plèvre seulement.
Pendant le mois suivant, on a évalué la réponse comportementale à des stimuli mécaniques, pincement et toucher, et la sensibilité au froid avec de l'acétone. De plus, une autoradiographie de la substance $P$ réalisée avec ${ }^{125}$ / a été utilisée pour déterminer la densité du récepteur de neurokinine (NK) dans les lames / et I/ de moelle épinière de une à six semaines après l'opération.

Résultats : Chez les rats avec ligature des nerfs, l'hypersensibilité à des stimuli nocifs ou non s'est poursuivie tout au long du mois. Le "phénomène miroir» a été observé. Le seuil le plus bas a été noté dans la portion dorsomédiane du dermatome T4 du côté de la ligature. Chez les rats aux côtes sectionnées, le seuil le plus bas aux stimuli nocifs ou non a été observé pendant deux semaines. Chez les rats qui ont subi une opération fictive, l'hypersensibilité n'a été observée que le jour suivant l'intervention. La densité du récepteur NK-I du côté de l'opération a augmenté significativement chez les rats aux nerfs ligaturés du jour sept au jour 28. La densité du récepteur a été plus élevée au jour $14\left(22,97 \pm 1,04 \mathrm{fmol} \cdot \mathrm{mg}^{-1}\right.$ de tissu vs le témoin, $16,22 \pm 0,43)$, ce qui représente un excès de récepteur de $50 \%$ du côté de la ligature comparé au côté opposé.

Conclusion : Une lésion du nerf intercostal induit une douleur postthoracotomie de longue durée et une augmentation des récepteurs médullaires de NK-I chez les rats. Ce modèle peut servir aux travaux de recherche sur la douleur post-thoracotomie.

$\mathrm{P}$ POSTTHORACOTOMY pain persists for several weeks, and often for several months; indeed, more than $55 \%$ of patients have pain one year after the operation. ${ }^{1}$ Persistent postthoracotomy pain is difficult to relieve, its causes are incompletely understood, and empiric therapy is often inadequate. Obata $e t$ al. reported that epidural block with mepivacaine before surgery reduces longterm postthoracotomy pain, thus demonstrating the effectiveness of preemptive epidural block. ${ }^{2}$ To date,

From the Department of Anesthesiology, Gunma University School of Medicine, Gunma, Japan.

Address correspondence to: Dr. Shigeru Saito, Department of Anesthesiology, Gunma University School of Medicine, 3-39-22 Showa,

Maebashi, Gunma, 371-8511, Japan. Phone: +81 027220 8454; Fax: +81 027220 8473; E-mail: shigerus@showa.gunma-u.ac.jp Accepted for publication January 4, 2001.

Revision accepted April 2, 2001. 
however, the mechanism underlying long-term postthoracotomy pain remains to be clarified both experimentally and clinically.

Various tissues are injured in the course of thoracotomy, including such proposed origins of pain as soft tissues, ribs, intercostal nerves, sympathetic paravertebral ganglions and pleura. ${ }^{3}$ Clinical symptoms of chronic postthoracotomy pain include allodynia, hyperalgesia, hypoesthesia (numbness at the injured site), and unprovoked burning pain. ${ }^{4,5}$ These characteristics are similar to those of neuropathic pain induced by damage to large nerves or the spinal cord, suggesting intercostal nerve damage as the primary cause of postthoracotomy pain. However, no report has established a relationship between a specific damaged tissue and postthoracotomy pain.

Models of several types of pain have been developed in animals, including peripheral nerve injuries, bone injury, inflammation of soft tissue (subcutaneous infusion of formalin, carrageenan, or capsicin), and metabolically induced neuropathy; specifically that associated with diabetes. In particular, the nerve injury models reported by Bennett, Seltzer, and Chung are very useful for studying mechanisms underlying neuropathic pain. ${ }^{6-8}$ In the Bennett and Seltzer models, the sciatic nerve is damaged. In the Chung model, the L5 and L6 spinal nerves are injured. Since these models were designed to provoke neuropathic pain in the lower limb, they cannot be applied to investigation of posthoracotomy pain.

In the present study, we attempted to develop an original rat model of postthoracotomy pain. Since the specific behavioural responses of rats to thoracic pain have not been demonstrated, we examined responses to a formalin injection in thoracic skin as an initial step. We then examined the topographic distribution of hypersensitivity and the time course of allodynialike symptoms after experimental intercostal nerve injury, in response to mechanical and thermal stimulation. For assessment of pain associated behaviours provoked by non-noxious mechanical stimulation, we used von Frey filaments. ${ }^{9}$ As a noxious stimulus, we used pinching with a forceps (Table I). In addition, we examined neurochemical changes of spinal dorsal horn neurokinin (NK)-1 receptors in rats with nerve damage, using a quantitative autoradiographic method.

\section{Materials and methods}

\section{Behavioural experiments}

I. SURGERY

All experimental procedures were approved by our Institutional Animal Use and Care Committee. Male Wistar rats 200 to $250 \mathrm{~g}$ were studied in all experi-
TABLE 1 Behavioural tests and parameters examined

\begin{tabular}{|c|c|}
\hline Tests & Variables \\
\hline \multicolumn{2}{|l|}{ Non-noxious } \\
\hline Touch & withdrawal threshold (g) \\
\hline (von Frey hair) & score for withdrawal behaviours \\
\hline Noxious & withdrawal $(0=$ no response; $1=$ escape \\
\hline Pinch & behaviour; \\
\hline (forceps) & $2=$ squeaking; $3=$ exaggerated response) \\
\hline Thermal & occurrences of scratching thoracic skin/min \\
\hline \multicolumn{2}{|l|}{$\begin{array}{l}\text { Cold } \\
\text { (acetone) }\end{array}$} \\
\hline General Observation & increased scratching of thoracic skin \\
\hline
\end{tabular}

ments. A bilateral patch of dorsal skin surrounding the $\mathrm{T} 4$ and $\mathrm{T} 5$ vertebrae was shaved under $\mathrm{O}_{2}$-isoflurane inhalation anesthesia. All procedures were performed using aseptic technique. Skin, fascial layer, and muscle layers were incised. The left fourth and fifth intercostal nerves were isolated carefully using a brunt probe. The pleura was incised for $3 \mathrm{~cm}$ along the intercostal nerves beginning at the nerve origin. Posterior and lateral cutaneous nerve branches were identified and carefully preserved. The initial segments of the intercostal nerves were ligated loosely using $4-0$ chromic gut suture filaments at two points $5 \mathrm{~mm}$ apart. Following ligation, the incision was closed in layers by silk sutures. Ribs were not traumatized. At the end of closure, a 20G-needle catheter was inserted into the thorax to aspirate air from the pleural cavity.

In the rats with sham operation, only the pleura along the fourth and fifth intercostal nerves was cut along a length of $3 \mathrm{~cm}$ with care not to damage the nerves.

In the rib-cutting operation, pleura along the fourth and fifth intercostal nerves was cut along a length of $3 \mathrm{~cm}$, the fourth and fifth ribs were cut with scissors at a point $1 \mathrm{~cm}$ distal to the head of the rib (not removed), with care not to damage the intercostal nerves.

\section{Behaviours CAUSED BY THORACIC SUbCUTA-} NEOUS INJECTION OF $\mathbf{5} \%$ FORMALIN

Withdrawal behaviours from thoracic pain in rats have not been characterized. Accordingly, to observe behaviours in response to pain in this regions, $5 \%$ formalin $(100 \mu \mathrm{L})$ was injected $s c$ in the area of the T4 dermatome in rats $(n=12)$. Escape behaviours were noted within ten minutes after the injection. As the response to formalin was not biphasic, we simply observed behaviours and counted their occurrence for ten minutes. 
III. Time COURSE OF WITHDRAWAL BEHAVIOUR Mechanical stimulation with von Frey filaments On days one, six, 13, 20, and 27 after surgery, response to touch stimulation was examined using von Frey filaments. Each rat was placed in a clear plastic box $(20 \times 20$ $\mathrm{x} 25 \mathrm{~cm}$ ) with a soft absorbent lining on the bottom. Rats were allowed to adapt to their environment for approximately $15 \mathrm{~min}$, until box exploration and major grooming activities had ceased. Testing was performed during the daytime, between 9 a.m. and 1 p.m. On the day before testing, a bilateral patch of dorsal skin surrounding the fourth and fifth thoracic vertebrae was shaved.

\section{(a) Threshold force required to reproduce behaviour seen with formalin injection}

Each filament was applied in a perpendicular orientation to both the incision site and the contralateral area dorsomedially within the T4 dermatome. The threshold was determined as the weakest force necessary to cause scratching behaviour followed by licking the hindpaw. Von Frey filaments were used beginning with those that apply the weakest force. The interval between application of different filaments from different stimuli was longer than one minute in all cases.

\section{(b) Semiquantitation of pain behaviour}

A von Frey filament marked as 4.17 (force $=1.479$ Newton; minimal mechanical stimulation which could provoke some withdrawal behaviours in the shamoperated rats.) induced the following six types of behaviour: scratching the stimulated site with the hindpaw, licking the hindpaw after scratching the stimulated site, jumping, squeaking, running away, and trembling. Each behaviour was counted as one point and the sum of the scores was recorded. The cutaneous stimulation point was dorsomedial in the T4 dermatome. Von Frey filaments with a number less than 4.17 provoked escape behaviour in all animals.

\section{Pinch testing}

The skin along the T4 dorsomedial dermatome was pinched with a pointed forceps on either the side of operation or the contralateral side. The pointed tips of the forceps were apposed for one second. Extent of tip movement involved in pinching was $5 \mathrm{~mm}$, and $2 \mathrm{~kg}$ of force at the sides of the forceps was required to appose the tips. Responses were scored as: $0=$ no response; $\mathrm{l}=$ =escape behaviour; $2=$ squeaking; and $3=$ exaggerated responses.

\section{Cold stimulation (acetone)}

To quantify cold sensitivity of the thorax, scratching behaviours related to the point where acetone con- tacted the skin were counted for one minute. A 500$\mu \mathrm{L}$ volume of $80 \%$ acetone at room temperature was dripped from a syringe with a 20G-Teflon needle onto the incision site and the contralateral zone representing the dorsomedial T4 dermatome from a height of $2 \mathrm{~cm}$ above the animal. The acetone was applied three times (once every two minutes) to each thoracic site; data are shown as the mean. The interval between stimulation of the side of operation and stimulation of the contralateral side was one minute.

\section{Distribution of Cutaneous hypersensi-} TIVITY

von Frey test

The dorsal thoracic area surrounding the T4 and T5 dermatomes was divided into 24 sectors as follows. Each side of the dorsal thoracic dermatomes T2 to T6 was divided equally into three parts. The section adjacent to vertebra was defined as medial. The site next to the medial sector was defined as middle, followed by the lateral sector. Threshold forces required to induce a scratching behaviour at the stimulated site, followed by licking the hindpaw, were measured in each sector 14 days after nerve-ligation operation or sham operation $(n=6)$.

\section{Cold stimulation (acetone)}

The test has been described by various authors. ${ }^{10-12}$ The thoracic area surrounding the T4 and T5 dermatome was divided into 16 sectors (T2 to T6; two sectors per side per dermatome). The sector nearest to the vertebra was defined as medial, with an adjacent sector defined as lateral. Spread of acetone precluded testing of 24 sectors as in the von Frey test. Occurrences of scratching at the point where the acetone contacted the skin were counted 14 days after nerve ligation or sham operation (each $n=6$ ).

\section{Neurochemical assessment: autoradiography of rat} spinal cord NK-I receptor

I. TISSUE PROCESSING

After the behavioural study, rats with intercostal nerve ligations or sham operations were anesthetized with $\mathrm{O}_{2}$ - isoflurane for two minutes and then decapitated. Spinal cords were removed quickly, frozen with $\mathrm{CO}_{2}$, and stored with O.C.T compound (Tissue Tek, Sakura Finetek, USA) at $-80^{\circ} \mathrm{C}$. Spinal cords were cut into transverse sections $20 \mu \mathrm{M}$ in thickness at T3, T4, T5, $\mathrm{T} 6$, and also at the lumbar level in a cryostat kept at $20^{\circ} \mathrm{C}$. The sections were affixed to poly-L-lysine-coated slides. All sections were stored at $-80^{\circ} \mathrm{C}$ prior to autoradiography. 
II. RECEPTOR BINDING

For NK-1 receptor binding, the sections were thawed, dried with cool air, and immersed in $0.05 \mathrm{M}$ Tris $\mathrm{HCl}$ $(\mathrm{pH} 7.4)$ containing $0.02 \%$ bovine serum albumin (BSA) for $15 \mathrm{~min}$ at room temperature. Sections used to determine total binding were transferred to $0.05 \mathrm{M}$ Tris $\mathrm{HCl}(\mathrm{pH}, 7.4)$ with $3 \mathrm{mM} \mathrm{MgCl} 2,4 \mathrm{mg} \cdot \mathrm{mL}^{-1}$ bacitracin, $4 \mathrm{mg} \cdot \mathrm{mL}^{-1}$ leupeptin, $2 \mathrm{mg} \cdot \mathrm{mL}^{-1}$ chymostatin, and 100 picomoles ${ }^{125} \mathrm{I}$-Bolton-Hunter substance P (BH SP $)^{11,12}$. This concentration of ${ }^{125} \mathrm{I}-\mathrm{BH}$ SP was chosen because a preliminary study had shown good detection of NK-1 receptors. Simultaneously, sections used to determine nonspecific binding were incubated in the same buffer with the addition of 1 $\mu \mathrm{M}$ unlabelled substance $\mathrm{P}$. The entire incubation procedure lasted for $45 \mathrm{~min}$. Sections then were washed in $0.05 \mathrm{M}$ Tris ( $\mathrm{pH} 7.4$ ) four times for $60 \mathrm{sec}$ each and quickly rinsed twice in deionized water (15 sec rinse). Sections subsequently were dried rapidly in a stream of cool air and desiccated overnight at room temperature. On the following day the sections were apposed to radiographic film (Hyperfilm $B$ Max, Amersham, Backinghamshine, England) in a Hypercassete (Amersham, Backinghamshine, England) and allowed to expose the film for 20 days at $-80^{\circ} \mathrm{C} .{ }^{125} \mathrm{I}-\mathrm{BH}-\mathrm{SP}$ standards were mounted on microscopic slides and placed in the same cassettes. Films were developed with D-19 (Kodak, Rochester, NY), fixed, and washed according to the manufacturer protocol.

\section{IMAgE ANALYSIS OF LAMinAE I AND II} Using a GT9000 scanner (Epson, Tokyo, Japan) and an image quantifier (Bio Image, Genomic Solutions, Tokyo, Japan), the autoradiograms were scanned and depicted at x 100 magnification on a super-fine pitch television monitor. Images of nonspecific binding were subtracted digitally from images of total binding to yield images of specific binding. Laminae I and II of the dorsal horn were chosen for quantitation; $;^{15}$ these laminae were defined by criteria reported by Molander $e t a l$. and Mao et al. ${ }^{16}$ Laminae I and II in the subtracted autoradiograms were traced, and the average optical density within the perimeter was determined. By comparing optical densities in spinal cord slices and those in ${ }^{125} \mathrm{I}-\mathrm{BH}$ SP standards, optical density values representing specifically bound ligand were converted to femtomoles of the ligand bound per milligram of wet tissue. A planimetric measurement was obtained for laminae I and II from the tissue section using the same anatomic criteria. In addition, optical density ratios of ligated side to contralateral sides were calculated, and changes in the ratios during the postoperative period were compared.

\section{Statistical analysis}

Behavioural assessment

Data from rats with intercostal nerve ligation were compared to findings in rats with sham operations and those with rib-cutting operations using the MannWhitney $U$ test. Data are expressed as the mean $\pm S D$. In rats with nerve ligation, data from the ligated side also were compared with data from the contralateral side using the Mann-Whitney $U$ test.

\section{Spinal cord NK-1 receptor autoradiography}

Values for NK-l receptor density in rats with nerve ligation and those with sham operation were analyzed in triplicate sections from each rat. Data represent the means \pm SD. Two-way analysis of variance (ANOVA) was used for statistical analysis, choosing a significance level of 0.05 . The NK-1 receptor ratio in the nerveligation group and those in the sham-operation group were analyzed using the Mann-Whitney $U$ test. Data at different time point were analyzed using KruskalWallis one-way ANOVA according to rank, again with significance at 0.05 .

\section{Results}

\section{Behavioural experiments}

I. BEHAVIOURS FOLLOWING SUBCUTANEOUS INJECTION OF $5 \%$ FORMALIN

Within ten minutes after formalin was injected $s c$ in dorsal thoracic skin, rats showed withdrawal responses. The biphasic changes described in the hindpaw test did not occur. ${ }^{17}$ Scratching at the injected point with the hindpaw followed by licking the hindpaw was observed in all injected rats (Table II).

\section{Time COURSE OF WITHDRAWAL BEHAVIOUR}

No visible signs of infection were present around the incision in any rat during the experiments.

For more than a month, rats occasionally showed intense scratching of the operative site while in their cages in the absence of mechanical stimulation.

TABLE II Behaviour following a thoracic subcutaneous injection of $5 \%$ formalin

\begin{tabular}{lll}
\hline Behaviour & Numbers of rats $(n=12)$ & Prevalence \\
\hline $\begin{array}{l}\text { Squeaking } \\
\text { Trembling }\end{array}$ & 10 & $83 \%$ \\
$\begin{array}{l}\text { Scratching at the } \\
\text { injected point }\end{array}$ & 12 & $92 \%$ \\
$\begin{array}{l}\text { Licking the hindpaw after } \\
\text { scratching at the } \\
\begin{array}{l}\text { injected point } \\
\text { Licking at the }\end{array}\end{array}$ & 11 & $100 \%$ \\
injected point & 9 & $100 \%$ \\
\hline
\end{tabular}


Fig 1

A.
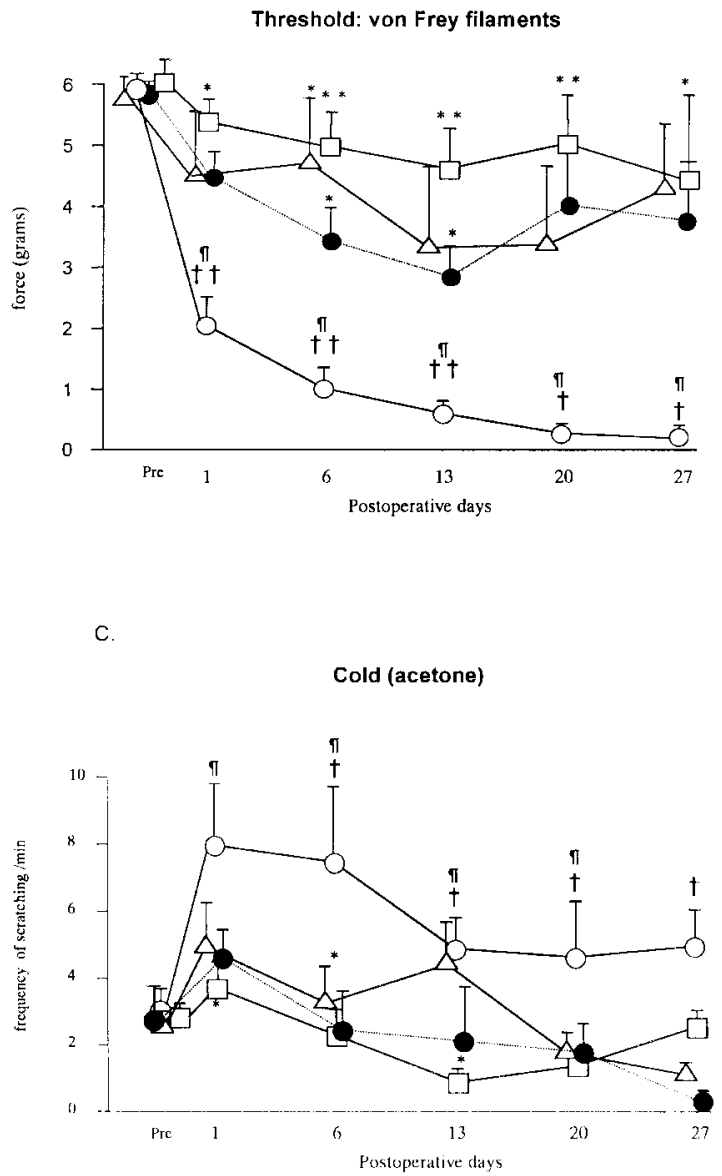

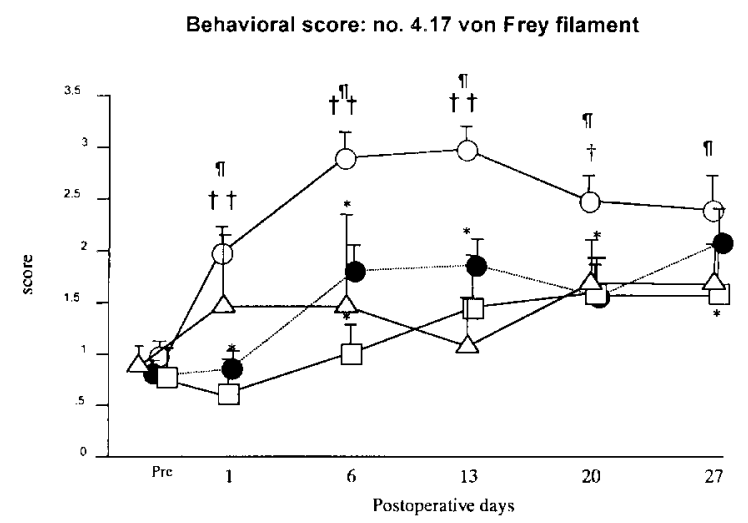

Pinch

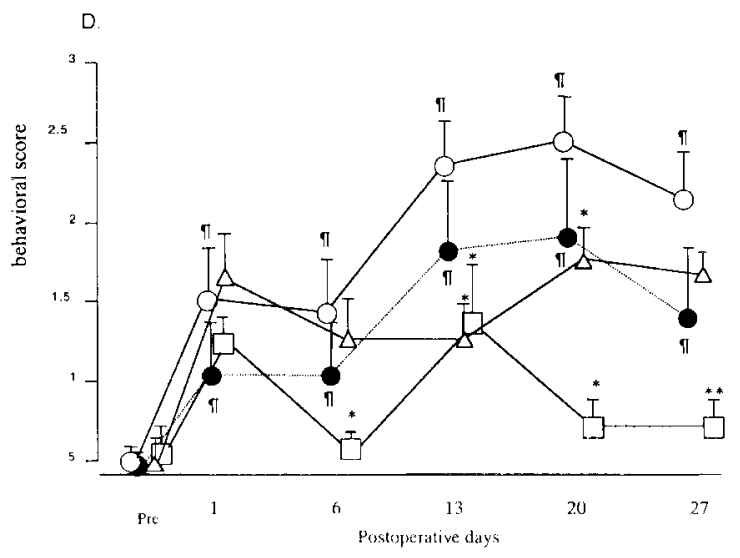

FIGURE 1 Behavioural changes in rats following surgery. Open circles represent values in rats with intercostal nerve ligation for stimulation on the side of operation; closed circles refer to stimulation on the contralateral side. Squares represent values in the sham-operation group for stimulation on the side of operation. Triangles represent values following the rib-cutting operation for stimulation on the side of operation. A, Threshold force required to induce scratching at the stimulated site followed by licking of the hindpaw. (POD $1 ; n=27$, POD 6; $n=27$, POD 13; $n=26$, POD 20; $n=7$, POD 27; $n=6$ ). B, Semi-quantitative score of pain behaviours. (POD 1; $n=33$, POD 6; $n=32$, POD $13 ; n=33$, POD $20 ; n=19$, POD 27; $n=8)$. C, Occurrences of scratching at the point of cold stimulation during one minute. (POD $1 ; n=18$, POD $6 ; n=18$, POD 13; $n=12$, POD 20; $n=7$, POD 27;n=7) D, Response to skin pinching. Data represent means \pm SD for each test. POD; postoperative day. $\dagger P<0.05 ; \dagger \uparrow P<0.01 v s$ contralateral side. $\llbracket P<0.05$ vs pre-operation value on the side of operation; ${ }^{*} P<0.05 ;{ }^{*} P<0.01$ vs ligation group.

Abnormal behaviours were observed in $70 \%$ of rats with loose chromic gut ligation of the nerve, while the remaining $30 \%$ showed hypoesthesia alone. Weak stimulation applied to the thoracic skin using von Frey filaments or pinching induced several behavioural responses. These responses were similar to those shown by rats receiving subcutaneous formalin injections.
1) Mechanical stimulation with von Frey filaments (a) Threshold force required to induce scratching followed by paw licking

On days one, six, 13, 20, and 27 following nerve ligation, significantly weaker stimulation was required on the side of the incision to induce a clear increase in scratching and licking than was required on the con- 
Fig. 2A.

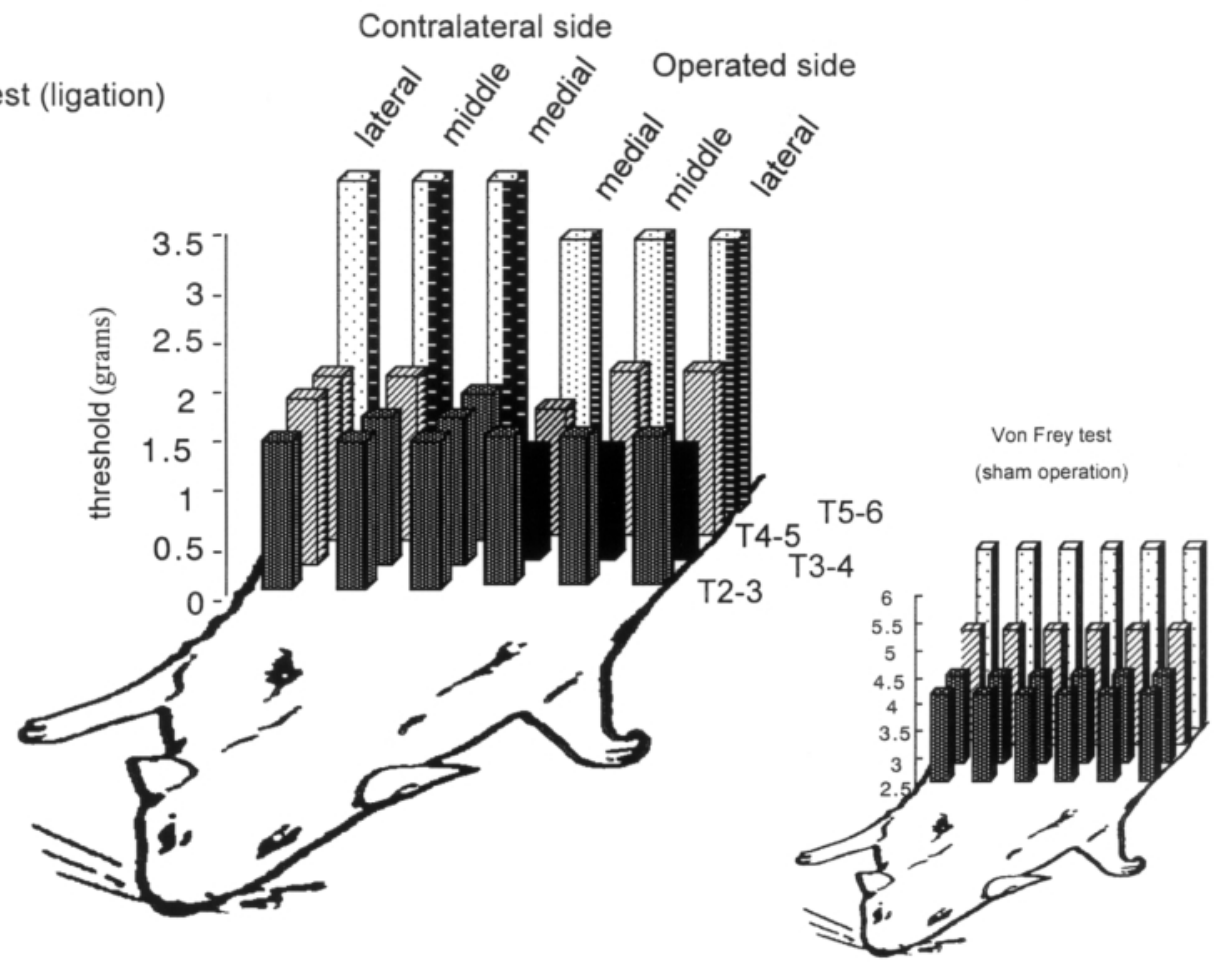

Fig. 2B.

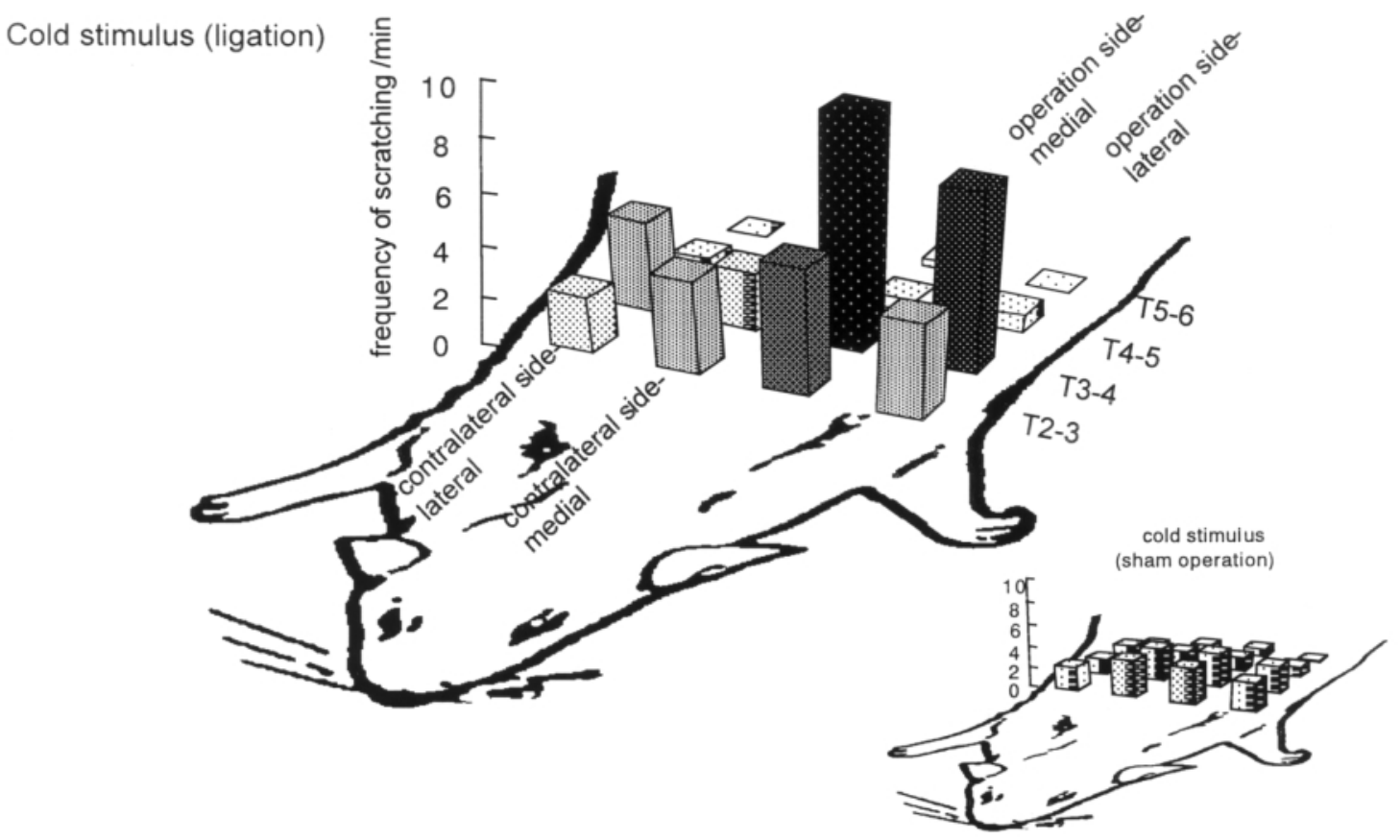

FIGURE 2 Spatial distribution of withdrawal behaviour. A, Threshold force for touch required to induce scratching at the stimulated site followed by licking of the hindpaw. The dorsal thoracic region surrounding T4 and T5 was divided into 24 sectors. Data represent mean values $(n=6)$.

B, Frequency of scratching at the point of cold stimulation during one minute. The dorsal thoracic region surrounding T4 and T5 was divided into 16 sectors. Data represent mean values $(n=6)$. 


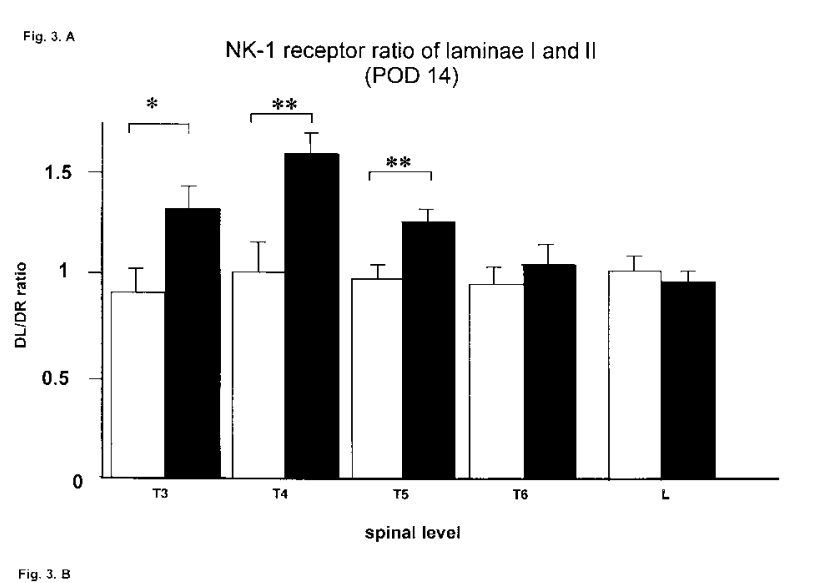

Fig. 3. B

$\mathrm{T} 4$
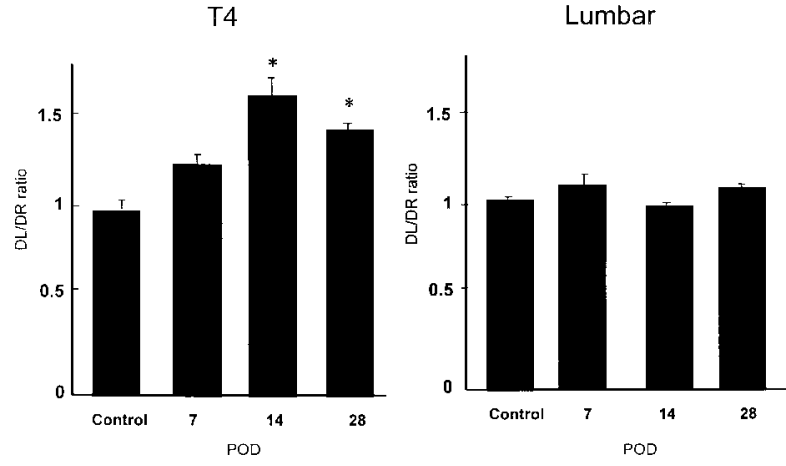

FIGURE 3 A, Neurokinin (NK)-1 receptor densities in the dorsal horn 14 days after operation. Binding densities were calculated as a ratio: density in the operated side / the value in the contralateral side. Solid bars represent specific binding receptor ratios for rats with intercostal nerve ligation; open bars depict ratios for sham-operated group. B, NK-1 receptor densities following nerve ligation at the T4 and lumbar level in spinal cord dorsal horn. Binding density ratios were calculated as above. NK=neurokinin; $\mathrm{DR}=$ right side of dorsal horn; DL=left side of dorsal horn.

tralateral side. In contrast, no significant differences were observed between the side operated upon and the contralateral side in rats with rib-cutting or sham operations rats at any time point (Figure 1A).

Sham-operation and rib-cutting groups did not differ significantly in threshold force on the side of operation. Thresholds in the nerve-ligation group were lower on the side of ligation than in the sham-operation group, at all time points. On days six, 13, 20, and 27 , thresholds in rats with nerve ligation were lower on the side of ligation than in rats with rib-cutting. In the nerve-ligation group, thresholds on the side of ligation were lower on postoperative days one, six, 13, 20 , and 27 than they were compared preoperatively. On the contralateral side, thresholds were decreased on day six and 13 after operation.

\section{(b) Semiquantitation of pain behaviour}

Mechanical stimulation with a von Frey filament (handle marking, 4.17; force, $1.479 \mathrm{~g}$ ) provoked a more pronounced reaction when applied to the ligated side than to the contralateral side, on postoperative days one, six, 13, and 27. On both sides, scores after surgery were higher than preoperatively (Figure 1B).

In the rib-cutting and sham-operation group, no difference between sides was observed. On the side of operation, no significant difference was seen between the sham-operation and rib-cutting group. Scores were higher in the ligation group than in the shamoperation group at all time points, and than in the ribcutting group on postoperative days six and 13 .

\section{2) Pinch testing}

On the side of operation on days six, 13, 20, and 27, pinch scores were significantly higher in the ligation group than in the sham-operation group. The nerveligation group showed a significantly greater response than the rib-cutting group only on postoperative day 13 (Figure 1D). No significant differences were noted between the side of operation and the contralateral side in any group. On both sides, the score after surgery was higher than preoperatively in the ligation group.

\section{3) Cold stimulation (acetone)}

Cold stimulation with acetone applied to the skin induced several behaviours including hindpaw licking, squeaking, running away, and momentary trembling. In rats with nerve ligation, scratching occurred more often when stimulation was applied to the side of operation than when cold was applied to the contralateral side (Figure lC). In the rib-cutting and sham-operation group, no such laterality was observed. No significant difference in response to cold stimulation was observed between the rib-cutting and the sham-operation group. Scratching was more frequent in the nerve-ligation than in the sham-operation group at all time point, and exceeded frequently that in the rib-cutting group, on day six (Figure 1C).

\section{CUtAneous Distribution OF WithdRAWAL} BEHAVIOUR

\section{1) von Frey test}

Threshold force required in rats with nerve ligation to induce scratching of the stimulated site and then licking of the hindpaw was lowest in T3 and 4 medial sectors on the side of operation. A low-threshold area extended cranially and caudally over the dorsal thorax on the site of operations and also extended contralaterally side. In the sham-operation group, no laterality was observed. (Figure 2A). 


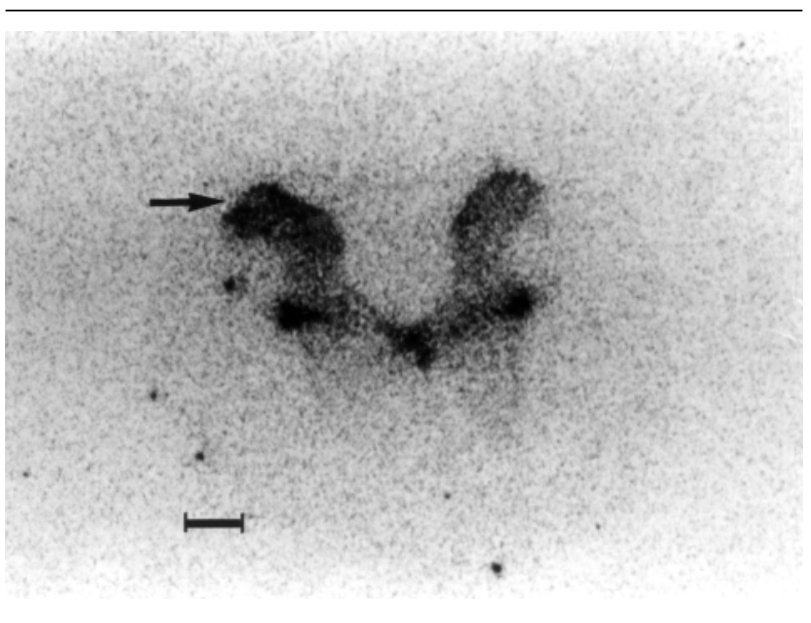

FIGURE 4 Neurokinin (NK)-1 receptor autoradiography of spinal cord. A rat with left intercostal nerve ligation at T4. Density of NK-1 receptors increased on the side of ligation (arrow). Bar $=300 \mu \mathrm{M}$.

\section{2) Cold stimulation (acetone)}

In the nerve-ligation group, frequency of scratching where the acetone contacted the skin was increased in the T3 to 4 medial sectors on the side of operation, indicating rostral spread of high scratching frequency. A minor increase in frequency also was observed on the contralateral side. In the sham-operated group, no laterality was observed (Figure 2B).

\section{Neurochemical assessment of spinal cord NK-1 recep- tors (Figure 4)}

Densities of NK-1 receptors before and after nerve ligation at T3 to 6 and in the lumbar spinal cord are shown in Table III. At T4 on the side of ligation, densities of NK-1 receptors were increased between the postoperative days seven and 28 , peak density occurred on day 14. Densities at T3 and T5 were increased only on day 14 . On the contralateral side, NK-1 receptors did not increase significantly. In the sham-operation group, the density of NK-1 receptors did not change through the experiments (Table IV).

On postoperative day seven, NK-1 receptor ratios for laminae I and II (nerve-ligation side/contralateral side) were not significantly increased at any level examined in the nerve-ligation group. On postoperative day 14 , the ratio was significantly increased at $\mathrm{T} 3, \mathrm{~T} 4$, and $\mathrm{T} 5$ (Figure $3 \mathrm{~A}$ ), by day 28, the ratio was significantly increased only at T4. Ratios at T6 and at the lumbar level did not change significantly at any time point.
At $\mathrm{T} 4$, the NK-1 receptor ratio reached its maximal value on postoperative day 14 (Figure 3B).

In the sham-operation group, the NK-1 receptor ratios remained $\mathrm{l}: 1$ at all time points.

\section{Discussion}

Long-term postthoracotomy pain, which is experienced by $60 \%$ of patients undergoing thoracic surgery, compromises patients' quality of life. Despite the clinical importance of the problem, adequate animal models for investigation of pathophysiologic mechanisms and experimental therapy of this condition have not been developed. To our best knowledge, this is the first report to describe a rat model of long-term postthoracotomy pain, although, several animal models have been established to examine mechanisms underlying neuropathic pain in the hindpaw. Bennett and Xie described a rat model, in which the sciatic nerves were loosely ligated using a chromic gut suture material. Seltzer et al. also have presented a partial sciatic nerve injury model in rats. Kim et al..$^{18}$ described another model, in which the L5 and L6 spinal nerve were tightly ligated using silk thread. With respect to pain originating in bone, Houghton et al. ${ }^{19}$ devised a rat model of postfracture pain by injuring the tibia.

In the present study we modified the hindpaw model devised by Bennett et al. In a preliminary study, we examined section of nerves, tight ligation using chromic gut suture material, and ligation with silk thread. These operations all caused hypoesthesia within one month, and abnormal behaviour could not be provoked in the rats by mechanical or thermal stimulation. Only loose ligation of intercostal nerves with chromic gut induced abnormal behaviours and decreased threshold to noxious stimuli beyond one month.

Bennett et al. and Chaplan et al. observed flinching, twitching, vocalization, and licking of the hindpaw in their neuropathic pain model. Kim et al. also observed similar behaviours in their model. According to Bossut et al. ${ }^{20}$ and Frenk et al. ${ }^{21}$ these behaviours have withdrawal characteristics and include emotional aspects of escape behaviour. In the preliminary study, dorsal thoracic subcutaneous injection of formalin induced specific behavioural responses. Some of them were similar to those seen with the hindpaw models. Thus, the abnormal behaviours observed in our nerveligation group were considered to include elements of an organized escape response. Licking of the hindpaw was observed, even though the stimulus was applied to the thorax. This behaviour appeared comparable to that observed with the hindpaw neuropathic model and we believe that, most likely, the animals in our 
TABLE III ${ }^{125} \mathrm{I}-\mathrm{BH}$ SP/NK-1 binding in the dorsal horn of the rat spinal cord following left intercostal nerve ligation

\begin{tabular}{|c|c|c|c|c|c|c|c|c|c|c|c|}
\hline \multirow{2}{*}{ Spinal level } & \multirow{2}{*}{ Spinal side } & \multicolumn{2}{|c|}{ Control $(n=6)$} & \multicolumn{2}{|c|}{ POD7 $(n=6)$} & \multicolumn{2}{|c|}{ PODI4 $(n=10)$} & \multicolumn{2}{|c|}{ POD28 $(n=9)$} & \multicolumn{2}{|c|}{ POD42 $(n=4)$} \\
\hline & & mean & $S D$ & mean & $S D$ & mean & $S D$ & mean & $S D$ & mean & $S D$ \\
\hline \multirow[t]{2}{*}{$\mathrm{T} 3$} & left & 14.49 & 0.65 & 14.27 & 2.59 & $19.28 \dagger$ & 1.01 & 16.51 & 1.86 & 15.42 & 1.70 \\
\hline & right & 14.92 & 1.08 & 15.57 & 2.59 & 15.06 & 0.92 & 15.66 & 1.73 & 15.20 & 2.21 \\
\hline \multirow[t]{2}{*}{$\mathrm{T} 4$} & left & 16.22 & 0.43 & $16.58 \dagger$ & 3.09 & $22.97 \dagger$ & 1.04 & $18.37 \dagger$ & 1.56 & 16.11 & 1.83 \\
\hline & right & 16.00 & 1.08 & 15.74 & 3.09 & 15.12 & 0.71 & 15.25 & 1.70 & 14.32 & 1.52 \\
\hline \multirow[t]{2}{*}{$\mathrm{T} 5$} & left & 15.35 & 1.30 & 15.57 & 1.56 & $16.75 \dagger$ & 2.51 & 17.10 & 2.19 & 16.58 & 1.26 \\
\hline & right & 16.22 & 1.30 & 15.18 & 1.95 & 15.11 & 2.37 & 14.85 & 1.96 & 14.73 & 1.16 \\
\hline \multirow[t]{2}{*}{ T6 } & left & 15.22 & 1.04 & 14.38 & 0.76 & 14.58 & 1.59 & 16.10 & 2.42 & 12.84 & 1.51 \\
\hline & right & 15.57 & 1.21 & 15.14 & 1.51 & 15.551 & 1.85 & 15.84 & 2.15 & 12.99 & 1.07 \\
\hline \multirow[t]{2}{*}{ Lumbar } & left & 16.43 & 2.14 & 14.27 & 1.95 & 16.11 & 8.20 & 16.63 & 2.46 & - & - \\
\hline & right & 15.45 & 1.70 & 14.27 & 1.95 & 15.04 & 8.39 & 16.60 & 2.32 & - & - \\
\hline
\end{tabular}

Data represent the mean and SD (femtomole per milligram of wet tissue). POD=postoperative day; BH SP=Bolton Hunter substance P; $\mathrm{NK}=$ neurokinin; $\dagger=P<0.05$ vs control.

TABLE IV Comparison between the symptoms of postthoracotomy pain in humans and the sensory disorders of the present model

\begin{tabular}{|c|c|c|}
\hline Variable & Long-term postthoracotomy pain & The present model \\
\hline 1. Cause & unknown & intercostal nerve loosely ligated \\
\hline 2. Onset & usually immediate & immediate \\
\hline 3. Duration & usually indefinite if untreated & at least $3 \mathrm{mo}$ \\
\hline 4. Contralateral phenomenon & "mirror image" pain & "mirror image" + \\
\hline 5. Relief by sympathectomy & sometimes effective & $?$ \\
\hline \multicolumn{3}{|l|}{ 6. Allodynia evoked by } \\
\hline Light touch & + & + \\
\hline Cold & + & + \\
\hline 7. Touch-evoked hyperesthesia & + & + \\
\hline 8. Heat-evoked hyperalgesia & $?$ & ? \\
\hline 9. Mechanical hyperalgesia & + tenderness & + \\
\hline 10. Spontaneous pain & + burning pain & + scratching the operated site without stimulus \\
\hline 11. Pain radiation & + & + \\
\hline
\end{tabular}

study experienced neuropathic pain. The animals in this study spontaneously showed behaviours associated with thoracic pain, even with no direct stimulation to the operating sites for approximately one month after surgery, for example, intense scratching at the incision site. Similarly, in the reported hindpaw experiments, spontaneous pain-related behaviours persisted for several weeks.

We used three methods to clarify the characteristics of the abnormal sensation in our model. Experiments with von Frey filaments demonstrated reactivity to mechanical stimulation, which depends on sensory transmission through A-beta fibres. Pain-related behaviours provoked by this non-noxious stimulus imply the presence of allodynia. Acetone cold testing demonstrates thermal sensitivity, which represents sensory transmission through A-delta or C fibres. Pinching with forceps is related to noxious stimulation, which represents sensory transmission through A-delta fibres. Accordingly, mechanical hyperalgesia represents an excessive response of A-delta fibres, while mechanical and thermal allodynia are related to $\mathrm{C}$ fibre hypersensitivity and central sensitization. ${ }^{22,23}$ On postoperative day one of the present study, all groups including the rib-cutting and sham-operation groups showed withdrawal behaviours to the three different types of stimulation. This means that immediately after surgery, including minor surgery such as the sham operation, abnormal responses are induced in A-beta, A-delta, and C fibres. However, after the second day following surgery, the sham-operation group showed responses to stimuli that were similar to those seen before surgery. In nerve-ligation and rib-cutting groups, abnormalities persisted. This observation is in agreement with that of Houghton et al., whose experimental postfracture pain was associated with hyperalgesia persisting beyond one day. These results imply that postthoracotomy pain in the first six days after surgery might result from a combination of bone pain and nerve damage. Hypersensitivity involving A-delta 
fibre and C fibres may be related to postthoracotomy pain in these first six days. Mechanical and thermal allodynia persisted for 28 postoperative days only in the nerve-ligation group, implying that after day six, nerve damage was the main cause of pain. Cross-talk between A-beta and C fibres, as well as central sensitization, may be involved in this phenomenon.

Asymmetric sensitivity to noxious and non-noxious stimuli was observed after nerve ligation. In rats without nerve damage, no such laterality was observed. Lateralization of abnormalities following ligation involved alterations not only on the side of nerve injury but also the contralaterally, representing the mirror phenomenon reported by Procappi and Kozin. ${ }^{24,25}$ According to these reports, the mirror phenomenon is derived from biochemical changes in the spinal cord and is specific for neuropathic pain. The mirror phenomenon observed in our nerve-ligation group supports the idea that intercostal nerve ligation induces neuropathic pain.

In our behavioural experiments, laterality of sensitivity was detected for non-noxious stimulation such as in the von Frey test and the cold test (acetone). Similarly, in our neurochemical assessments, we detected a change in the distribution of NK-1 receptors in laminae I and II in the spinal cord following injury to the intercostal nerve.

Quantitative analysis of autoradiographic images indicated that the number of NK-l receptors increased on the damaged side, while the number on the contralateral side remained stable. This pattern of alteration in NK-1 receptors has been reported in the hindpaw deafferentation nerve model of Croul et al. and rat dorsal rhizotomy model of Yashpal et al. ${ }^{26} \mathrm{In}$ both models, NK-1 receptors increased in laminae I and II on the deafferented side for seven days after surgery, remaining elevated until day 14 and then returning to control levels by day 42 . The similar receptor changes observed in our model imply similar relations between behavioural and neurochemical changes in these studies. The mechanism of neuropathic pain is yet to be completely elucidated. For that reason, the detailed mechanisms linking behavioural change and neurochemical change remain unclear.

Table IV summarizes our observations in the present rat model, and compares them to symptoms in human postthoracotomy pain. We observed withdrawal responses to light touch using von Frey filaments in rats. A similar phenomenon is seen in patients with chronic postthoracotomy pain when cloth lightly touches the involved dermatome. When rats with intercostal nerve ligation were stimulated with pinching, they showed behaviours indicating mechanical hyperalgesia, which would correspond to tenderness in postthoracotomy patients. In humans, a burning sensation occurs intermittently with no stimulus; in the present model, rats showed scratching and licking without stimulation, suggesting spontaneous pain.

To date, several other neurochemical alterations have been reported in various hindpaw models. Several authors ${ }^{27-29}$ have reported alterations in substance $\mathrm{P}$ in dorsal root ganglion neurons and the dorsal column. Ma et al..$^{30}$ and Marchand et al. ${ }^{31}$ demonstrated respectively increases in preprotachykinin mRNA and substance $\mathrm{P}$ immunoreactivity in dorsal root ganglion neurons following partial sciatic nerve injury and chronic constriction injury. ${ }^{32}$ Although we focussed on alterations in NK-1 receptors in the present study, additional intracellular signals may have been altered in our postthoracotomy pain model. N-methyl- D-aspartate (NMDA) and non-NMDA glutamate receptors, which recently have been linked to neuropathic pain, may be among these altered proteins. ${ }^{33}$ Intracellular signal cascade enzymes, such as protein kinase-C (PKC), microtubule-associate protein (MAP) kinase and G-protein coupled proteins (GRKs), are also likely affected by nerve injury. ${ }^{34-36}$ Further neurochemical analysis of our model may provide considerable new information concerning neuropathic pain in the thoracic region.

We report an original animal model for the study of postthoracotomy pain in which rats showed abnormal behavioural reactions to mechanical and thermal stimuli, and intercostal-nerve injury provoked an important neurochemical change in the spinal cord.

\section{References}

1 Dajczman E, Gordon A, Kreisman H, Wolkove N. Long-term postthoracotomy pain. Chest 1991; 99 : 270-4.

2 Obata H, Saito S, Fujita N, Fuse Y, Ishizaki K, Goto F. Epidural block with mepivacaine before surgery reduces long-term post-thoracotomy pain. Can J Anesth 1999; 46: 1127-32.

3 Kavanagh BP, Katz J, Sandler AN. Pain control after thoracic surgery. Anesthesiology 1994; 81: 737-59.

4 Conacher ID. Percutaneous cryotherapy for post-thoracotomy neuralgia. Pain 1986; 25: 227-8.

5 Conacher ID. Pain relief after thoracotomy. Br J.Anesth 1990; 65: 806-12.

6 Bennett GJ, Xie $\Upsilon$-K. A peripheral mononeuropathy in the rat that produces disorders of pain sensation like those seen in man. Pain 1988; 33: 87-107.

7 Seltzer Z, Dubner R, Shir $\Upsilon$. A novel behavioral model of neuropathic pain disorders produced in rats by partial sciatic nerve injury. Pain 1990; 43: 205-18.

8 Carlton SM, Lekan HA, Kim SH, Chung JM. 
Behavioral manifestations of an experimental model for peripheral neuropathy produced by spinal nerve ligation in the primate. Pain 1994; 56: 155-66.

9 Chaplan SR, Bach FW, Pogrel JW, Chung JM, Yaksh TL. Quantitative assessment of tactile allodynia in the rat paw. J Neurosci Methods 1994; 53: 55-63.

10 Choi $\Upsilon$, roon $\Upsilon W$, Na HS, Kim SH, Chung JM. Behavioral signs of ongoing pain and cold allodynia in a rat model of neuropathic pain. Pain 1994; 59: 369-76.

11 Laughlin TM, Vanderah TW, Lashbrook J, et al. Spinally administered dynorphin A produces long-lasting allodynia: involvement of NMDA but not opioid receptors. Pain 1997; 72: 253-60.

12 Poybia R, Xu M, Kontien VK, Paananen S, Kalso E. Systemic physostigmine shows antiallodynic effects in neuropathic rats. Anesth analg 1999; 89: 428-33.

13 Croul S, Sverstiuk A, Radvievsky SA, Murray M. Modulation of neurotransmitter receptors following unilateral L1-S2 deafferentation: NK1, NK3, NMDA, and $5 \mathrm{HTl}$ a receptor binding autoradiography. J Comp Neurol 1995; 361: 633-44.

14 Kar S, Quirion R. Neuropeptide receptors in developing and adult rat spinal cord: an in vitro quantitative autoradiography study of calcitonin gene-related peptide, neurokinins, $\mu$-opioid, galanin, somatostatin, neurotensin and vasoactive intestinal polypeptide receptors. J Comp Neurol 1995; 354: 253-81.

15 Molander C, Grant G. Spinal cord cytoarchitecture. In: Paxinos G. (Ed.). The Rat Nervous System, 2nd ed. San Diego: Academic Press Inc., 1995: 39-45.

16 Mao J, Mayer DJ, Hayes RL, Price DD. Spinal patterns of increased spinal cord membrane-bound protein kinase $\mathrm{C}$ and their relation to increases in ${ }^{14} \mathrm{C}-2$ Deoxyglucose metabolic activity in rats with painful peripheral mononeuropathy. J Neurophysiol 1993; 70: 470-81.

17 Dubuisson D, Dennis $S G$. The formalin test: a quantitative study of the analgesic effects of morphine, meperidine, and brain stem stimulation in rats and cats. Pain 1977; 4: 161-74.

$18 \mathrm{Kim}$ SH, Chung JM. An experimental model for peripheral neuropathy produced by segmental spinal nerve ligation in the rat. Pain 1992; 50: 355-63.

19 Houghton AK, Hewwitt E, Westlund KN. Enhanced withdrawal responses to mechanical and thermal stimuli after bone injury. Pain 1997; 73: 325-37.

20 Bossut D, Frenk $H$, Mayer DJ. Is substance P a primary afferent neurotransmitter for nociceptive input? II. Spianalization does not reduce and intrathecal morphine potentiates behavioral responses to substance P. Brain Res 1988; 455: 232-9.

21 Frenk $H$, Bossut D, Urca GD. Is substance P a primary afferent neurotransmitter for nociceptive input? I.
Analysis of pain-related behaviors resulting from intrathecal administration of substance $P$ and 6 excitatory compounds. Brain Res 1988; 455: 223-31.

22 Cousins JM, Bridenbaugh PO. Neural blockade. In: Cousins JM, Bridenbaugh PO (Eds.). Neural Physiology and Local Anesthetic Action, $3^{\text {rd }}$ ed. New York: Lippincott-Raven, 1998; 35-54.

23 Campbell JN, Raja SN, Meyer RA, Mackinnon SE, Myelinated afferents signal the hyperalgesia associated with nerve injury. Pain 1988; 32: 89-94.

24 Procacci $P$, Maresca $M$. Reflex sympathetic dystrophies and algodystrophies: historical and pathogenic considerations. Pain 1987; 31: 137-46.

25 Kozin F, McCarty DJ, Sims J, Genant H. The reflex sympathetic dystrophy syndrome. I. Clinical and histologic studies: evidence for bilaterality, response to corticosteroids and articular involvement. Am J Med 1976; 60: 321-30.

26 rashpal K, Dam TV, Quirion R. Quantitative autoradiographic distribution of multiple neurokinin binding sites in rat spinal cord. Brain Res 1990; 506: 259-66.

27 Kajander KC, Xu J. Quantitative evaluation of calcitonin gene-related peptide and substance $P$ levels in rat spinal cord following peripheral nerve injury. Neurosci Lett 1995; 186: 184-8.

28 Tamatani $M$, Senba E, Tobyama $M$. Calcitonin generelated peptide- and substance $\mathrm{P}$-containing primary afferent fibers in the dorsal column of the rat. Brain Res 1989; 495: 122-30.

29 Noguchi K, Kawai Y, Fukuoka T, Senba E, Miki K. Substance $P$ increased by peripheral nerve injury in primary afferent sensory neurons and its effect on dorsal column nucleus neurons. J Neurosci 1995; 15: 7633-43.

$30 \mathrm{Ma} W$, Bisby $M A$. Increase of preprotachykinin mRNA and substance $\mathrm{P}$ immunoreactivity in spared dorsal root ganglion neurons following partial sciatic nerve injury. Eur J Neurosci 1998; 10: 2388-99.

31 Marchand JE, Wurm WH, Kato T, Kream RM. Altered tachykinin expression by dorsal root ganglion neurons in a rat model of neuropathic pain. Pain 1994; 58 : 219-31.

32 Fukuoka T, Tokunaga A, Kondo E, Miki K, Tachibana $T$, Noguchi K. Change in mRNAs for neuropeptides and the $\mathrm{GABA}_{\mathrm{A}}$ receptor in dorsal root ganglion neurons in a rat experimental neuropathic pain model. Pain 1998; 78: 13-26.

33 Ma QP, Woolf CJ. Noxious stimuli induce N-methyl-Daspartate receptor-dependent hypersensitivity of the flexion of withdrawal reflex to touch: implications for the treatment of mechanical allodynia. Pain 1995; 61: 383-90.

34 Polgar E, Fowler JH, McGill MM, Todd AJ. The types of neuron which contain protein kinase $\mathrm{C}$ gamma in 
rat spinal cord. Brain Res 1999; 833: 71-80.

35 Mao J, Price DD, Phillips LL, Lu J, Mayer DJ. Increases in protein kinase $\mathrm{C}$ gamma immunoreactivity in the spinal cord dorsal horn of rats with painful mononeuropathy. Neurosci Lett 1995; 198: 75-8.

36 Zhang J, Ferguson SSG, Law P- , Barak LS, Caron MG. Agonist-specific regulation of $\delta$-opioid receptor trafficking by $\mathrm{G}$ protein-coupled receptor kinase and $B$-arrestin. J Recept Signal Transduct Res 1999; 19: 301-13. 